\title{
MENINGKATKAN MOTIVASI KONSUMEN MEMBELI PRODUK LOKAL DI KOTA JAMBI
}

\author{
Asrini $^{1}$, Musnaini ${ }^{2}$ \\ ${ }^{1}$ STIE Mumahadiyah Jambi, ${ }^{2}$ Universitas Jambi \\ e-mail : assrini@gmail.com¹, mussnaii_@gmail.com²
}

\begin{abstract}
Abstrak
Tujuan Penelitian, menganalisis pengaruh motivasi utilitarian (cost saving, dan selection), terhadap brand attitude dan selanjutnya memoderasi dan memedisi terhadap purchase intention pada produk lokal di Jambi. Metode penelitian menggunakan kuantitatif. Model penelitian mengembangkan model Motivation-Opportunity-Ability (MOA). Antesedan motivasi utilitarian menggunakan dimensi (cost saving, dan selection). Responden penelitian adalah konsumen yang berbelanja produk batik Jambi di kota Jambi. Jumlah sampel penelitian sebanyak 110 responden. Metode pengumpulan data dilakukan dengan kuesioner, dan di ukur menggunakan skala linkert 1-5. Alat analisis data menggunakan Path Analysis Model dengan software SPSS. Temuan empiris membuktikan motivasi utilitarian mempunyai pengaruh positif dan signifikan terhadap brand attitude pada taraf $5 \%$ dan purchase intention pada taraf $15 \%$. Brand attitude mempunyai pengaruh positif dan signifikan terhadap purchase intention pada taraf $5 \%$. Motivasi utilitarian berpengaruh signifikan terhadap purchase intention melalui brand attitude dan selanjutnya memperkuat purchase intention pada produk lokak (batik Jambi).
\end{abstract}

Kata kunci: Motivasi Utilitarian, Saving, Selection, Brand Attitude, Purchase Intention, Batik Jambi

\section{Abstract}

The purpose of the study, to analyze the influence of utilitarian motivation (cost saving, and selection), to brand attitude and then to moderate and memed to purchase intention on local product in Jambi. The research method used quantitative. The research model developed the MotivationOpportunity-Ability (MOA) model. Antecedents of utilitarian motivation use dimensions (cost saving, and selection). Research respondents are consumers who shop Jambi batik products in Jambi city. The number of research samples are 110 respondents. Methods of data collection were conducted with questionnaires, and measured using a 1-5 linkert scale. Data analysis tool using Path Analysis Model with SPSS software. The empirical finding proves that utilitarian motivation has positive and significant influence on brand attitude at $5 \%$ level and purchase intention at $15 \%$ level. Brand attitude has a positive and significant influence on purchase intention at $5 \%$ level. Utilitarian motivation significantly influences purchase intention through brand attitude and further strengthens purchase intention on the products of lokak (Jambi batik).

Keywords: Utilitarian Motivation, Saving, Selection, Brand Attitude, Purchase Intention, Jambi Batik 


\section{Pendahuluan}

Dalam beberapa tahun terakhir, perilaku konsumen membeli produk batik lokal cenderung menurun, hal tersebut terkait dengan banyaknya produk batik dari luar daerah yang bersaing ketat di pasar konsumen Jambi. Harga dan kualitas merupakan anteseden penting mempengaruhi sikap merek dan purchase intention (Kaplan and Haenlein, 2010). Assael (2001) membuktikan bawha brand attitude berpengaruh positif untuk membangun hubungan yang kuat dengan konsumen (Huges, 2007). Oleh karena itu penting bagi produsen batik lokal untuk memahami faktor-faktor yang mendasari purchase intention konsumen, termasuk memahami motivasi, sikap dan niat untuk membuat strategi pemasaran yang tepat.

Perilaku konsumen merupakan kunci utama untuk memprediksi kebutuhan konsumen (Hawkins, et al 1986). Memahami perilaku pemebelian dapat di jelaskan oleh aspek motivasi (Solomon, 2015). Motivasi merupakan penentu utama keputusan pembelian (Hawkins, et al 1986). Secara spesifik, motivasi adalah keadaan pendorong seseorang mengarah pada perilaku dan tujuan tertentu yang teraplikasi pada aktivitas belanja utilitarian dan hedonik (Solomon, 2015). Hirschman, et al., (1982) mengklasifikasi motivasi utilitarian atauhedonik. Utilitarian lebih didasarkan pada alasan functional atau tangible, sedangkan hedonik lebih bersifat pleasurable atau intangible (Solomon, 2015).

Hirschman et al., (1982) mengatakan bahwa motivasi utilitarian timbul karena ada kebutuhan yang dirasakan oleh konsumen. Fungsi utilitarian lebih didasarkan pada alasan functional atau tangible (Solomon, 2015). Sedangkan menurut (Mikalef et al., 2012) utilitarian mengacu pada manfaat yang didapat bergantung pada efisiensi selama proses akuisisi. Konsumen yang berorientasi belanja dan berperilaku utilitarian, mereka biasanya membeli produk berbasis pada kebutuhan rasional yang berhubungan dengan tujuan tertentu (Kim and Shim, 2002). Oleh karena itu interaksi konsumen untuk tujuan utilitarian dengan merek tertentu akan berbeda karena tujuan personal dan motivasinya berbeda.

Berdasarkan model MOA (Maclnnis and Jaworski,1989) motivasi anteseden penting penentu keputusan pembelian dengan tujuan tertentu. Salah satu alasan seseorang untuk membeli produk atau jasa dikarenakan motivasi utilitarian yaitu: cost saving yang merupakan tingkatan manfaat biaya yang diberikan oleh media sosial kepada penggunanya (Kaplan and Haenlein, 2010; Childers et al., 2001; To et al., 2007), dan selection merupakan kemampuan menyediakan variasi produk (To et al.,2007).

Konsumen bermotivasi utilitarian atau berorientasi dengan tujuan akan mencari informasi produk atau jasa yang sesuai dengan kebutuhan personal merek (Jamiszewski,1998). Menurut Assael (2001) siikap terhadap merek adalah kecenderungan yang dipelajari oleh konsumen untuk mengevaluasi merek dengan cara mendukung (positif) atau tidak mendukung (negatif) secara konsisten. Variable ini diukur dengan menggunakan dimensi sikap terhadap merek yaitu tentang pernyataan mental menerima pesan yang menilai positif atau negative, bagus-tidak bagus, suka-tidak suka, berkualitas-tidak berkualitas suatu produk (Assael, 2001 : 82). Menurut Mikalef et al., (2013) purchase intention mengacu pada niat konsumen untuk membeli produk yang telah mereka lihat. Kerangka model penelitian yang dikembangkan untuk penelitian ini adalah sebagaimana pada gambar 1 . 


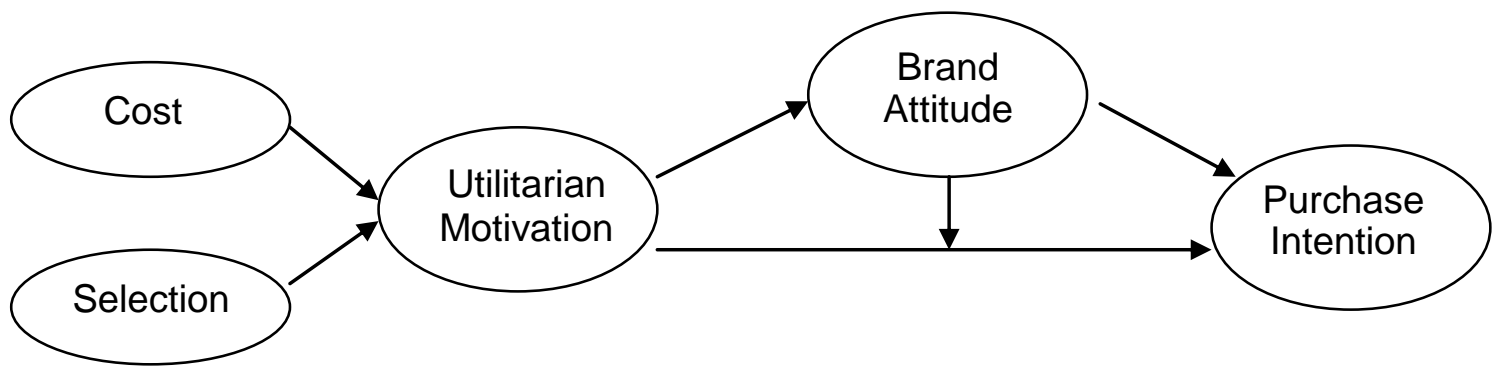

Gambar 1. Kerangka Konsep Penelitian

Penelitian ini bertujuan untuk menganalisis faktor-faktor utilitarian yang mempengaruhi sikap merek dan pada akhirnya akan mempengaruhi purchase intention. Penelitian ini menggunakan Model Motivation, Opportunity, ability (MOA). Konstruksi model menggunakan motivasi utilitarian adalah cost saving, dan selection, sikap merek dan purchase intention.

\section{Metode}

Pendekatan penelitian ini adalah penelitian kuantitatif. Untuk menguji hipotesis menggunakan teknik analisis path analysis model dengan software SPSS. Menguji hipotesis pengaruh motivasi utilitarian terhadap sikap merek (brand attitude). Menguji efek brand attitude yang memoderasi motivasi utilitari terhadap purchase intention. Populasi penelitian adalah konsumen yang mengenal batik di kota Jambi. Sedangkan sampel penelitian adalah konsumen yang pernah membeli batik Jambi dalam 6 bulan terakhir. Pengumpulan data melaui kuisioner yang dirancang untuk memuat pernayataan dan di isi oleh responden. Kuisioner menggunakan 5 poin skala Likert dan dibagi menjadi tiga bagian. Bagian pertama didesain untuk memperoleh informasi demografis dari responden, bagian kedua didesain untuk mengukur pengaruh motivasi utilitarian, dan bagian ketiga didesain untuk mengukur dampak motivasi utilitarian tersebut terhadap sikap merek dan niat pembelian (Mikalef et al., 2012).

Definisi operasional variabel pada penelitian ini adalah menjelaskan variabel motivasi utilitarian (cost saving dan selection), brand attitude, dan purchase intention. Definisi Operasional Cost saving adalah tingkatan manfaat biaya yang diberikan oleh produk lokal kepada konsumennya. (Kaplan and Haenlein (2010). Selection adalah kemampuan menyediakan variasi produk. Utilitarian motivation Tingkatan dimana pembeli memperoleh nilai manfaat dari fungsi utama produk (Mikalef et al. 2013; To et al, 2007).

Brand attitude adalah sikap mental suka atau tidak suka konsumen terhadap merek (Huges, 2007). Purchase Intention adalah niat konsumen untuk membeli produk yang telah mereka lihat.(Bian et al., 2011; Mikalef et al, 2013). Penelitian ini menggunakan model Motivasi-Opportunity-Ability $(M O A)$ yang telah dikembangkan oleh peneliti sebelumnya, dimana alasan seseorang untuk belanja melalui media sosial dikarenakan motivasi utilitarian yaitu cost saving, dan selection. salah satu alasan seseorang untuk membeli produk dikarenakan motivasi utilitarian yaitu: cost saving yang merupakan tingkatan manfaat biaya yang diberikan oleh media sosial kepada penggunanya (Kaplan and Haenlein, 2010) dan selection merupakan kemampuan menyediakan variasi produk (Mikalef et al., 2013).

Konsumen yang berorientasi belanja dan berperilaku utilitarian, mereka biasanya berbelanja berbasis pada kebutuhan rasional yang berhubungan dengan tujuan tertentu (Kim and Shim, 2002). Sikap merek dimana kemampuan konsumen mengevaluasi merek (baik buruk) yang memberikan manfaat nilai untuk mencapai tujuan personal. Mikalef et al., (2013) purchase intention mengacu pada niat konsumen untuk membeli produk yang telah mereka lihat. Rumusan hipotesis sebagai berikut: 
H1: Motivasi utilitarian (cost saving dan selection) mempunyai pengaruh signifkan terhadap purchase intention

H2: Motivasi utilitarian (cost saving dan selection) mempunyai pengaruh signifkan terhadap brand attitude.

H3: Motivasi utilitarian (cost saving dan selection) mempunyai pengaruh signifikan terhadap purchase intention melalui brand attitude.

H4: Efek moderasi brand attitude memperkuat pengaruh motivasi utilitarian (cost saving dan selection) terhadap purchase intention.

\section{Hasil dan Pembahasan}

Eksplorasi niat pembelian konsumen produk lokal berupa batik Jambi. Data penelitian di analisis menggunakan SPSS versi 18. Ada tiga tahapan yaitu analisis deskripsi data, analisis validitas dan reliabilitas, analisis jalur (path analysis) dengan regresi bertingkat. Setiap kuesioner diuji untuk mengetahui apakah seluruh data yang akan diuji telah memenuhi persyaratan sebagai indikator dalam penelitian. Skala pengukuran item pertanyaan menggunakan range antara skor 1-5, supaya tidak terdapat data yang outlier, maka setiap butir dalam kuesioner di uji secara statistik. Hasil pengujian indikator variabel seperti pada Tabel 1.

Tabel 1. Deskripsi Indikator variabel

\begin{tabular}{cccccc}
\hline & N & Minimum & Maximum & Mean & $\begin{array}{c}\text { Std. } \\
\text { Deviation }\end{array}$ \\
\hline X11 & 110 & 2.00 & 5.00 & 3.7241 & .93874 \\
X12 & 110 & 2.00 & 5.00 & 3.6280 & .83652 \\
X13 & 110 & 2.00 & 5.00 & 3.8641 & .94624 \\
X21 & 110 & 2.00 & 5.00 & 3.7534 & .93806 \\
X22 & 110 & 1.00 & 5.00 & 3.5403 & 1.27031 \\
X23 & 110 & 1.00 & 5.00 & 3.4256 & .96072 \\
Y11 & 110 & 2.00 & 5.00 & 3.7580 & .93811 \\
Y12 & 110 & 1.00 & 5.00 & 3.6280 & .82861 \\
Y13 & 110 & 1.00 & 5.00 & 3.7435 & .95630 \\
Y21 & 110 & 2.00 & 5.00 & 3.5925 & .93801 \\
Y22 & 110 & 1.00 & 5.00 & 3.5496 & .83827 \\
Y23 & 110 & 2.00 & 5.00 & 3.6271 & .94624 \\
Y24 & 110 & 2.00 & 5.00 & 3.3324 & .93806 \\
Valid N & 110 & & & & \\
(listwise) & 110 & & & \\
\hline
\end{tabular}

Pada Tabel 1 menggambarkan bahwa 100\% responden mengisi seluruh butir kuesioner dengan skor nilai 1 sampai dengan skor 5 . Nilai rata-rata minimal 3,33 dan maksimal 3,86 dan nilai standard deviasi minimal 0,82 dan maksimum 1,27 sehingga seluruh butir penelitian layak untuk dibuat data penelitian karena tidak ada nilai standard deviasi yang lebih besar dari nilai rata-ratanya.

Deskripsi analisis pengaruh motivasi utilitarian terhadap brand attitude dan Purchase intention seperti pada tabel 2. Jumlah data reponden yang diuji sebanyak 110 orang, Rata-rata dan standard deviasi untuk masing-masing variabel adalah variabel Purchase intention mempunyai rata-rata 3,56 dan standard deviasi 0,72 , Variabel Motivasi Utilitarianmempunyai rata-rata 3,70 dan standard deviasi 0,745 , variabel brand attitude mempunyai rata-rata 3,56 dan standard deviasi 0,85 . Tabel 2 dibawah menampilkan nilai deskripsi data masing masing variabel yang diteliti. 
Tabel 2. Deskrisi Variabel Penelitian

\begin{tabular}{lccc}
\hline & Mean & Std Deviasi & N \\
\hline Purchase Intention & 3.4297 & .730518 & 110 \\
Utilitarian Motivation & 3.8261 & .760130 & 110 \\
Brand Attitude & 3.5302 & .858303 & 110 \\
\hline
\end{tabular}

Pada Tabel 2, memberikan informasi bahwa semua variabel penelitian tidak ada outlier. Artinya bahwa pengujian variabel layak untuk menjawab hipotesis yang telah di rumuskan. Hasil analisa data menunjukkan nilai ratarata seluruh variabel di antara nilai 3,42 sampai dengan 3,82 lebih besar dari nilai tengah range skor antara 1 sampai dengan 5 yaitu sebesar 2,5 . Nilai standard deviasi variabel antara 0,73 sampai 0,85 lebih kecil dari nilai rata-rata.

Tabel 3. Uji Validitas Indikator Variabel

\begin{tabular}{ccc}
\hline & Correlation & Keterangan \\
\hline X11 & .711 & $>0,164 ;$ Valid \\
X12 & .720 & $>0,164 ;$ Valid \\
X13 & .768 & $>0,164$ Valid \\
X21 & .687 & $>0,164 ;$ Valid \\
X22 & .789 & $>0,164 ;$ Valid \\
X23 & .781 & $>0,164$ Valid \\
Y11 & .435 & $>0,164 ;$ Valid \\
Y12 & .892 & $>0,164 ;$ Valid \\
Y13 & .602 & $>0,164$ Valid \\
Y21 & .846 & $>0,164 ;$ Valid \\
Y22 & .760 & $>0,164 ;$ Valid \\
Y23 & .857 & $>0,164$ Valid \\
Y24 & .806 & $>0,164 ;$ Valid \\
\hline
\end{tabular}

Dari Tabel 3 di atas, memberikan pemahaman bahwa variabel motivasi Utilitarian (X1) menggunakan diuji dengan menggunakan 2 indikator variabel yaitu cost saving dan selection dengan enam dimensi. Secara keseluruhan di lakukan pengujian validitas dan reliabilitas terhadap indikator variabel motivasi Utilitarian. Validitas butir variabel motivasi utilitarian pada output SPSS dilihat pada nilai Corrected Item-Total Correlation jika nilainya lebih besar dari $r$ tabel $(n=110, d f=n-2=100$ rtabel=0,164) maka dikatakan bahwa butir variabel adalah valid (Santoso, 2010).

Tabel 4. Uji Reliabilitas Variabel Penelitian

\begin{tabular}{lcc}
\hline & $\begin{array}{c}\text { Cronbach's } \\
\text { Alpha if Item } \\
\text { Deleted }\end{array}$ & Keterangan \\
\hline Purchase Intention & 0.897 & $>0,164 ;$ Reliabel \\
Utilitarian Motivation & 0.926 & $>0,164 ;$ Reliabel \\
Brand Attitude & 0.830 & $>0,164 ;$ Reliabel \\
\hline
\end{tabular}

Tabel 4, menampilkan hasil uji reliabilitas untuk indikator variabel yang diteliti, seluruh indikator memiliki Cronbach's Alpha lebih besar dari $r$ tabel 0,164, sehingga seluruh variabel adalah reliabel. Uji validitas dan reliabilitas indikator variabel telah memenuhi persyaratan dan layak. Maka penelitian ini melanjutkan analisis untuk melihat seberapa kuat pengaruh variabel motivasi Utilitarian, brand attitude terhadap Purchase intention pada produk batik Jambi. 
Hasil analisis Path (jalur) menemukan pengaruh variabel motivasi utilitarian (cost saving dan selection) terhadap terhadap Purchase intention dengan di moderasi dan mediasi oleh brand attitude dalam keputusan pembelian produk lokal yaitu batik Jambi dapat di olah lebih lanjut. Uji analisis jalur menggunakan software SPSS versi 18 dengan analisis Regresi linier bertingkat. Tahap pertama menguji pengaruh motivasi ulitarian dan brand attitude terhadap Purchase intention dan tahap kedua menguji pengaruh motivasi utilitarian terhadap purchase intention melalui brand attitude. Ketiga menguji motivasi terhadap purcahe intention di moderasi brand attitude.

Tabel 5.Koefisien analisa jalur Motivasi Utilitarian terhadap Purchase intention

\begin{tabular}{llcc}
\hline \multicolumn{1}{c}{ Eksogen } & \multicolumn{1}{c}{ Endogen } & Koef & Sig. \\
\hline Cost Saving & Brand Attitude & 0,738 & 0,000 \\
Cost Saving & Purchase Intention & 0,601 & 0,000 \\
BrandAattitude & Purchase Intention & 0,782 & 0,000 \\
Brand Attitude & Purchase Intention & 0.763 & 0.00 \\
Selection & Brand Attitude & 0,802 & 0,000 \\
Selection & Purchase Intention & 0,760 & 0,000 \\
Brand Attitude & Purchase Intention & 0.658 & 0,000 \\
Brand Attitude & Purchase Intention & 0,796 & 0.000 \\
\hline
\end{tabular}

Tabel 5, menyajikan hasil uji analisa jalur pengaruh motivasi utilitarian secara langsung terhadap purchase intention dan pengaruh motivasi utilitarian terhadap purchase intention melalui brand attitude serta pengaruh motivasi utilitarian terhadap purchase intention di moderasi brand attitude.

Hasil analisis jalur membuktikan bahwa motivasi utilitarian ( cost saving) berpengaruh positif terhadap Purchase intention konsumen membeli produk lokal berupa Batik Jambi, pengaruh tersebut yaitu sebesar 0,601 , dan selection sebesar 0,760 . Sedangkan pengaruh motivasi melalui brand attitude sebesar 0,782, dan sikap merek memperkuat pengaruh motivasi utilitarian terhadap keputusan pembelian pada produk lokal, yaitu batik jambi. Dengan demikian $\mathrm{H} 1, \mathrm{H} 2, \mathrm{H} 3$ dan $\mathrm{H} 4$ diterima dan terbukti secara empiris mampu menjelaskan perilaku pembelian konsumen pada produk lokal.

Hasil empiris membuktikan bahwa aspek motivasi berpengaruh signifikan terhadap brand attitude dan niat pembelian. Tidak ada perbedaan signifikan pengaruh motivasi secara langsung terhadap niat pembelian dengan mediasi brand attitude. Namun, pengaruh cost saving yang di mediasi brand attitude lebih dominan dari pada indikator selection. Artinya tanpa sikap merek, konsumen berniat membeli produk lokal dengan harga yang terjangkau dan ekonomis.

Secara teoritis hasil empiri dapat memberikan gambaran bahwa perilaku pembelian konsumen sangat di pengaruh seberapa besar motivasi utilitarian memberikan manfaat nilai terkait biaya yang dikeluarkan dan kemampuan produk memenuhi kebutuhan utama dari fungsi produk, sehingga membentuk sikap positif terhadap merek lokal. Konsumen dengan sikap positif terhadap merek lokal, memperkuat niat beli pada batik Jambi. Selanjutnya bahwa konsumen akan semakin kuat berkeinginan membeli produk lokal, khususnya batik jambi disaat mereka mempunyai sikap merek yang positif. 


\section{Simpulan dan Saran}

Dari paparan empiri dan teoritis membuktikan bahwa motivasi utilitarian berpengaruh terhadap purchase intention melalui sikap merek, dan selanjutnya brand attitude memperkuat niat pembelian konsumen produk lokal.

Penelitian ini memiliki keterbatasan, tidah hanay motivasi utilitarian yang mejadi pertimbangan atau pendorong seseorang melakukan keputusan pembelian, tetapi ada aspek psikologis, yaitu motivasi hedonik. (Arnold, and Reynolds, (2003). Selain itu, berdasarkan teori MOA penelitian ini memiliki kelemahan karena belum mempertimbangkan aspek peluang sebagai penentu perilaku konsumen. Maka untuk peneliti selanjutnya diharapkan dapat memprediksi perilaku pembelian dengan menambah motivasi hedonik dan aspek situasional (opportunity) dalam model MOA (Maclnnis, and Price, 1987; Huges, 2007).

\section{Daftar Rujukan}

Arnold, M. J. \& Reynolds, K. E.(2003). Hedonic shopping motivations.Journal of Retailing, 7795

Bian, Xuemei and Luiz Moutinho. (2011). The Role of Brand Image, Product Involvement and Knowledge. European Journal of Marketing, 191-216

Childers, T. L., Carr, C. L., Peck, J., and Carson, S. (2002). Hedonic and utilitarian motivations for online retail shopping behavior.Journal of Retailing, 77 (4), 511-535

Hirschman E.,C \& Holbrook M.B. (1982). Hedonic Consumption: Emerging concepts, methods and proposition.Journal of Marketing, 46(2), 92-101

Hughes, J. 2007. The ability -motivation -opportunity framework for behavior research in IS," 40th Annual Hawaii International Conference on Systems Science.

Jamiszewski, C., 1998. The influence of display characteristics on visual exploratory search behavior. Journal of Consumer Research, 25 (3), 290-301

Maclnnis, D.I. and Price, L.L. (1987). The Role Of Imagenery in Information Processing: Review And Extensions. Journal Of Consumer Research, 47- 491

Santoso, Singgih. (2010). Statistik Parametrik.Konsep dan Aplikasi dengan SPSS. Elex Media Komputindo, Jakarta.

Schiffman, Leon G., Leslie Lazar Kanuk \& Joseph Wisenblit. (2010). Consumer Behaviour Global. 10th Edition. New Jersey. Pearson

Solomon, R.M. (2015). Consumer Behavior: Buying, Having, and Being (11thed). Prentice Hall.

To, Pui-Lai., Liao, Chechen.,\& Lin, Tzu-Hua (2007). Shopping Motivations on Internet: A Study Based on Utilitarian and Hedonic Value. Technovation, Vol. 27 774-787

Kaplan, A. M. and Haenlein, M. (2010). Users of the world, unite The challenges and opportunities of social media. Business Horizons, 53(1), 59-68.

Kim, Y.M., Shim, K.Y., (2002). The influence of intent shopping mall characteristics and user traits on purchase intent. Iris Marketing Review, 15 (2), 25-34. 
Mikalef, Patrick., Michail, Giannakos, and Pateli, Adamatia.(2012). Exploring the business potential of social media: An utilitarian and hedonic motivation approach, in Proceedings of the 25th Bled eConference eDependability: Reliable and Trustworthy eStructures, eProcesses, eOperations and eServices for the Future Proceedings, Bled, Slovenia, 114.

Mikalef, Patrick., Michail, Giannakos and Pateli, Adamatia. (2013). Shopping and Word-ofMouth Intentions on Social Media. Journal of Theoretical and Applied Electronic Commerce Research, 8(1), 17-34. 